\title{
Use of potentially driver-impairing drugs among older drivers
}

\author{
Sarah Zitoun ${ }^{1,2}$, Edouard Baudouin ${ }^{3}$, Emmanuelle Corruble ${ }^{1,2}$, Jean-Sébastien Vidal ${ }^{4,5}$, \\ Laurent Becquemont ${ }^{1,2}$ and Emmanuelle Duron ${ }^{1,3^{*}}$
}

\begin{abstract}
Background: Road safety is a major issue among seniors. Potentially Driver-Impairing (PDI) drugs are known to increase the risk of car accident. The aim of this cross-sectional study was to describe PDI-drug consumption among older drivers and determine associated factors.

Methods: The S.AGES cohort is a French non-interventional real-life prospective study of 3700 community-dwelling participants aged $\geq 65$ years old, suffering from type 2 diabetes (T2DM), chronic pain or atrial fibrillation (AF). Baseline data of drivers with known treatment $(n=1783)$ were used for the analyses. PDI drugs were defined according to the French classification.

Results: One thousand seven hundred eighty-three drivers were included (66\% males; mean age 76 (Standard deviation $=5.78)$ years old $) .21 \%(n=373)$ took PDI drugs, $64 \%$ of which took only one $(n=239)$. The most frequent PDI drugs were: Zolpidem (11\%; $n=60)$; Zopiclone (8\%; $n=45)$; Bromazepam (8\%; $n=44)$; Tramadol $(7 \% ; n=39)$; Pregabalin (6\%; $n=31)$. Drivers taking PDI drugs had more often chronic pain (OR [95\% CI] $=2.30[1.54-3.46])$, history of depressive disorder (4.28 [3.00-6.14]) and polypharmacy (taking at least 5 different medications; 4.32 [2.97-6.41]), and less often T2DM (0.54 [0.37-0.79]), and AF (0.48 [0.32-0.71]). Conversely, they had a lower Activities of Daily Living score $(0.34$ [0.17-0.68]).
\end{abstract}

Conclusions: The rate of aged drivers in the S.AGES cohort taking PDI drugs is concerning and highlights the need to carefully assess and reassess PDI-drug prescriptions in this population, particularly hypnotics, anxiolytics and opioids.

Trial registration: ClinicalTrials.gov NCT01065909 (First posted: February 9th, 2010).

Keywords: Driving, Potentially driver-impairing drugs, Older people, Primary care

\section{Background}

Worldwide population aged 65 and older will double in 2050: it will reach 1.5 billion by then. In Europe and Northern America, a 48\% increase is projected. Moreover, the worldwide number of subjects aged 80 and older will triple to reach 426 million in 2050 [1].

\footnotetext{
*Correspondence: emmanuelle.duron@aphp.fr

${ }^{1}$ University of Paris-Saclay, Inserm, CESP, Team MOODS, 94270 Le Kremlin-Bicêtre, France

Full list of author information is available at the end of the article
}

Driving among older people is a matter of great concern. According to the Insurance Institute for Highway Safety, the proportion of the population $\geq 70$ years old with driving licenses in United States (US) grew from $73 \%$ in 1997 to 83\% in 2018 [2]. In European Union (EU) by 2030, a quarter of licensed drivers will be aged 65 and older [3]. Furthermore, even though older driver involvement rate in traffic accident globally declined these last couple of years $[4,5]$, older drivers remain significantly implicated in car accidents. In 2017, in the US, the number of fatal car accident per million miles traveled was 2.1 for drivers aged 75-79 and reached 7.6 for drivers aged 
85 and older [2]. In 2013, in EU, 20\% of all deaths among car drivers involved older people [3].

Aging is associated with altered physiological functions and diseases that can impair ability to drive, like visual impairments, musculoskeletal disorders, diabetes, dementia [6], depression [6, 7], and use of psychotropic drugs $[7,8]$. Potentially modifiable factors that could alleviate the risk of car accident in older people are of interest. In this way, Potentially Driver-Impairing (PDI) drugs consumption among older drivers ought to be studied. To date, real life data on driving in older people are scarce in France, particularly concerning the use of PDI drugs.

The objective of this study was to describe the use of PDI drugs among older drivers of the S.AGES cohort, and to analyze factors associated with their consumption.

\section{Methods}

\section{Population}

The S.AGES study is a French non-interventional reallife prospective study that included participants from April 2009 to June 2011. Characteristics of the cohort have already been published [9]. A total of 3700 community-dwelling participants aged 65 and older have been included by 760 French general practitioners (GP). The cohort was composed of 3 sub-cohorts: participants suffering from type 2 diabetes (T2DM), chronic pain or atrial fibrillation (AF). Investigators were randomized into one of the 3 sub-cohorts and could only include participants in the sub-cohort they had been randomized to. Each investigator included $1 / 3$ of participants aged $65-75$ years old, and $2 / 3$ of participants aged 75 and older. Participants were assessed by their GP every 6 months for 3 years. The study was approved by the Ethics committee (Comité de protection des personnes Ile de France XI) on January 15, 2009 (ref 09006) and by the French National Agency for Medicines and Health Products (ANSM) on February 6, 2009 (ref B81333-40) (ClinicalTrials.gov NCT01065909).

The inclusion criteria were: community-dwelling adult aged 65 and older; resident in metropolitan France; covered by health care insurance; who signed the informed consent form and affected by one of the 3 following conditions: confirmed AF within 12 months before inclusion; pain for more than 3 months and requiring care; T2DM treated at inclusion by an oral and/or injectable anti-diabetic medication.

The exclusion criteria were: nursing home resident at the time of inclusion; unable to understand the goal of the study and to give informed consent; impossible follow-up after inclusion (moving planned, homeless); already included in another therapeutic trial; non-cardiovascular disease with less than 3-month life expectancy; transient AF (related to thyrotoxicosis, excessive alcohol consumption, myocarditis, pericarditis, acute phase of myocardial infarction, pulmonary embolism, metabolic disorders, electrocution) and AF following heart surgery within 3 months before inclusion.

Socio-demographic, clinical and treatment data were recorded at inclusion, and updated at each visit except for driving status.

The socio-demographic data were: age, sex, smoking status (never, former, current), alcohol consumption (daily alcohol consumer or not), living environment (rural (or semi-rural) or urban area), living arrangement (at home alone or with spouse, or in an assisted living facility), driving status (active driver or not, according to participants' answer at the yes/no question "Do you drive a motorized vehicle?", with no detail required about frequency of driving nor having a driver's license) at inclusion, educational level (achievement $\geq 9$ th grade or less), work history, disability assessed by the Activities of Daily Living scale (ADL, maximum score 6 indicating no disability in activities of daily living) [10] and the Instrumental Activities of Daily Living scale (IADL, maximum score 4 indicating no instrumental disability) [11], financial or logistical supports, and paramedical assistance (home nursing care, pedicure or physiotherapy).

The clinical data recorded were: participant's apparent age (younger than, same as, or older than participant's chronological age) according to GP's gut feeling, body mass index (BMI, $\mathrm{kg} / \mathrm{m}^{2}$ ), estimated glomerular filtration rate (eGFR in $\mathrm{mL} / \mathrm{min} / 1.73 \mathrm{~m}^{2}$, calculated by the Modification of Diet in Renal Disease formula) [12], cardiovascular diseases (arterial disease, AF, high blood pressure, heart failure with severity assessed by the New York Heart Association (NYHA) classification), neurological diseases (Parkinson's disease, history of severe stroke, cognition assessed by the Mini-Mental State Examination (MMSE, maximum score 30 indicating no cognitive impairment) [13], psychiatric disorders (probable clinical depression assessed by a score $\geq 10$ at the 15 -item Geriatric Depression Scale (GDS-15, maximum score 15, the higher, the more important risk of depression) [14], history of depressive disorder), and several other medical conditions: thyroid dysfunction, T2DM, history of severe hypoglycemia (within less 12 months before inclusion), respiratory diseases (sleep apnea, chronic obstructive pulmonary disease (COPD) or pulmonary fibrosis), arthropathy (symptomatic osteoarthritis or chronic inflammatory rheumatic disease), history of falls (within 12 months before inclusion) and chronic pain.

The original study provided precise information about medications prescribed at baseline: name (International Nonproprietary (INN) name or trade one), Anatomical Therapeutic Chemical Classification System (ATC) code, dosage, therapeutic indication, number of unity per 
intake, number of intake per day, start and end dates of prescription [9]. In this study, treatment data recorded were the use of at least one PDI drug and polypharmacy (defined here as taking at least 5 different medications) [15]. Based on the ATC codes, each molecule was classified as PDI drug according to the French classification that distinguishes 3 levels of warning:

- level 1: low risk at driving; the drug intake does not contraindicate driving, but drivers are recommended to read the drug notice;

- level 2: pharmacodynamic effects of the drug predominates over individual susceptibility; the drug intake may alter driving ability; driving requires the advice of a health professional;

- and level 3: pharmacodynamic effects of the drug highly contraindicate driving; driving again requires the advice of a medical practitioner [16] (see Additional file 1).

In this study, a drug was classified as "PDI drug" if it was categorized at level 2 or 3 of the French classification, as level 1 does not contraindicate driving.

Among the 3700 participants included in the original cohort, 266 were excluded because they did not meet inclusion criteria or because of data unavailability [9]. Among the 3434 remaining participants, 25 were excluded because of unknown driving status. Among the 3409 remaining participants, 1565 were excluded because they were non-drivers. Among the 1844 drivers,
61 were excluded because of unknown PDI status (having at least one PDI drug in their treatment or not). Only drivers with information on their PDI status at baseline $(n=1783)$ were included in this cross-sectional analysis of the S.AGES study (Fig. 1). Drivers were categorized according to their use of PDI drugs: drivers taking at least one PDI drug (PDI+); drivers without any PDI drug in their treatment (PDI-).

\section{Statistics}

All statistical analyses were performed with the R Software (version 4.0.3; R Core Team (2019). R: A language and environment for statistical computing. $\mathrm{R}$ Foundation for Statistical Computing, Vienna, Austria. URL https:// www.R-project.org/). The descriptive parameters for the qualitative variables are presented as counts and percentages. The descriptive parameters for the quantitative variables are presented as means and standard deviations (M (SD)). Normal distribution hypotheses were tested using Shapiro-Wilk tests. The relationships between the dependent variable (PDI status) and the participants' characteristics were first tested using Chi-squared test or Fisher's exact test for categorical data, and Student's t-test or non-parametric Mann-Whitney test for continuous data. Quantitative variables with missing values accounting for $10 \%$ or more of the sample were not included in the analyses. All variables with a $p$-value $<0.10$ in univariate analysis were selected for the multivariate one, after a pre-selection on their correlation. Then a logistic regression model was built with PDI status as dependent

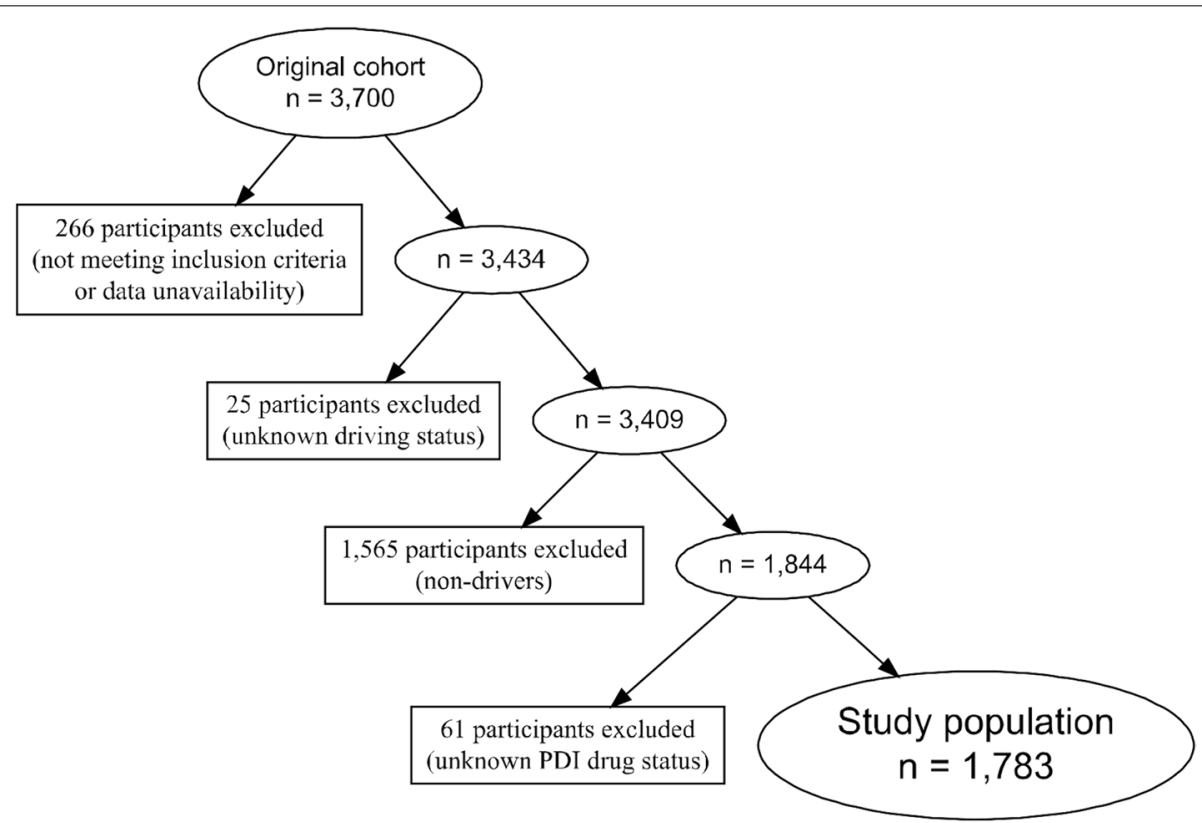

Fig. 1 Flowchart of the study population. Abbreviation. PDI, Potentially Driver-Impairing 
variable by a stepwise selection of the independent variables on complete observations. The final model was adjusted for all clinically relevant variables from the literature, and for T2DM, AF and chronic pain in order to take into account the possible selection bias induced by sub-cohorts. The adjusted odds ratios (OR) were calculated with their 95\% confidence intervals (95\% CI). Two-sided $p$-values $<0.05$ were considered statistically significant.

\section{Results}

In this S.AGES study, 1783 drivers had information on their PDI-drug consumption at baseline. Their characteristics at baseline are detailed in Table 1, as a whole and according to their PDI status. A third of the drivers were included in the chronic pain sub-cohort $(n=595)$, a third in the AF sub-cohort $(n=603)$, and a last third in the T2DM sub-cohort $(n=585)$. Mean age was 75.9 (5.8) years old, 65.5\% $(n=1168)$ were males and $20.9 \%$ $(n=373)$ were PDI+. Most of the PDI+ drivers took only one PDI drug (64.1\%; $n=239$ ) (Fig. 2). The most frequently prescribed PDI drugs were: Zolpidem (10.7\%; $\mathrm{n}=60)$; Zopiclone (8\%; $n=45)$; Bromazepam (7.8\%; $n=44)$; Tramadol (6.9\%; $n=39)$; Pregabalin (5.5\%; $n=31)$.

In multivariate analysis, the final model was adjusted for age, sex, history of depressive disorder, polypharmacy, ADL score, T2DM, AF and chronic pain. PDI+ drivers had more often chronic pain (OR $[95 \% \mathrm{CI}]=2.30$ [1.543.46]), history of depressive disorder (4.28 [3.00-6.14]) and polypharmacy (4.32 [2.97-6.41]), and less often T2DM (0.54 [0.37-0.79]), and AF (0.48 [0.32-0.71]). Moreover, PDI+ drivers had a lower Activities of Daily Living score (0.34 [0.17-0.68]) (Table 2 and Fig. 3).

\section{Discussion}

In this study, more than $20 \%$ of drivers were treated with at least one PDI drug $(n=373)$. The most frequent PDI drugs prescribed to drivers were Z-drug hypnotics (Zolpidem and Zopiclone), one anxiolytic (Bromazepam) and analgesics (Tramadol and Pregabalin). Compared to drivers without any PDI drug in their treatment, PDI+ drivers had more disability and more often a history of depressive disorder and were receiving more often polypharmacy. They had more frequently chronic pain and less frequently T2DM and AF.

The percentage of PDI+ drivers in this study was lower than in previous research. A study conducted in U.S. among 2990 older drivers aged 65-79years old found that $70 \%$ were under central nervous system agent [17]. Another one found $68.9 \%$ of PDI drug consumers among 225 drivers (mean age: 68 (12.8) years old) [18], according to the PDI medication list defined by Leroy and Morse in 2008, which includes not only central nervous system agents but also numerous other system agents (hematologic, cardiovascular-renal, gastrointestinal, metabolic, hormonal, neurologic, ophthalmic, otologic, antiparasitic, respiratory and analgesic ones) [19]. These discrepancies may be explained by the fact that not all central nervous system agents were taken into account in the present study, but only those impairing driving performance according to the French classification [16] (see Additional file 1). Furthermore, the studies of Hetland et al. and Hill et al. included medically impaired drivers referred to an occupational therapy-based driving evaluation clinic inflating in all likelihood the rate of PDIdrug consumption [17, 18]. Also, self-medication was not assessed in this study which can have minimized the prevalence of PDI-drug consumption, whereas self-medication is frequent in the older population [20], especially analgesics [20], and in France, benzodiazepines [21], both of them being PDI drugs.

In this study, the most frequent PDI drugs were Z-drug hypnotics (Zolpidem (10.7\%) and Zopiclone (8\%)), followed by one benzodiazepine (Bromazepam (7.8\%), and analgesics (Tramadol (6.9\%) and Pregabalin (5.5\%)). These results are consistent with previous research. One study found that Zopiclone and Diazepam were the two most frequent single legal drugs found in blood samples of older drivers suspected of driving under the influence of drugs. In this study, ethanol was detected in $81 \%$ of blood samples, Zopiclone in $9.8 \%$ and Diazepam in 9.3\% [22]. In the study of Hetland et al. in 2014, benzodiazepines, opioids and non-benzodiazepine hypnotics accounted respectively for $6.6,4.5$ and $4 \%$ of PDI drugs used among the 225 drivers [18]. Benzodiazepines are overprescribed in older people [21, 23], particularly in the treatment of insomnia and anxiety disorders, which are both frequent in older adults [24, 25]. Non-benzodiazepine hypnotics, known as Z-drugs (Zopiclone and Zolpidem for example) are also commonly used to treat insomnia because they are often perceived as safer than benzodiazepines, while they are associated with an increased risk of falls and fractures [26]. Moreover, older subjects frequently suffer from chronic pain [27, 28], which can explain the high rates of opioid use in this population $(6-9 \%)[27,29]$. Opioid misuse is also frequent in older people (1-3\%) [29], perhaps because of mood modifying effects of opioid agents, which are known to increase serotonin levels and cause addiction [30].

Our study found several factors associated with PDIdrug consumption. First, taking at least one PDI drug was associated with polypharmacy, which is frequently observed in older people [31-33]. Second, PDI-drug consumption was associated with history of depressive disorder and chronic pain, which is consistent with 
Table 1 Descriptive and univariate analyses of factors associated with PDI-drug consumption in drivers

\begin{tabular}{|c|c|c|c|c|c|}
\hline General characteristics, \% (n) & Missing, \% (n) & $\begin{array}{l}\text { All } \\
n=1783\end{array}$ & $\begin{array}{l}\text { PDI- } \\
n=1410\end{array}$ & $\begin{array}{l}\text { PDI+ } \\
n=373\end{array}$ & $p^{a}$ \\
\hline Sub-cohorts & $0(0)$ & & & & $<0.001$ \\
\hline Chronic pain & & $33.37(595)$ & $28.37(400)$ & $52.28(195)$ & \\
\hline Atrial fibrillation & & $33.82(603)$ & $36.88(520)$ & $22.25(83)$ & \\
\hline Type 2 diabetes & & $32.81(585)$ & $34.75(490)$ & $25.47(95)$ & \\
\hline Males & $0(0)$ & $65.51(1168)$ & $68.94(972)$ & $52.55(196)$ & $<0.001$ \\
\hline Age, M (SD) & $0(0)$ & $75.88(5.78)$ & $75.98(5.74)$ & $75.52(5.93)$ & 0.254 \\
\hline Apparent age & $0.28(5)$ & & & & 0.010 \\
\hline$<$ Chronological age & & $23.84(425)$ & $24.89(351)$ & $19.84(74)$ & \\
\hline$=$ Chronological age & & $68.93(1229)$ & $68.65(968)$ & $69.97(261)$ & \\
\hline >Chronological age & & $6.95(124)$ & $6.17(87)$ & $9.92(37)$ & \\
\hline BMI, M (SD) & $3.48(62)$ & $28.18(4.76)$ & $28.17(4.67)$ & $28.22(5.09)$ & 0.793 \\
\hline eGFR, M (SD) & $0.18(328)$ & $73.64(20.43)$ & $73.83(20.17)$ & $72.91(21.39)$ & 0.472 \\
\hline Smoking status & $0.45(8)$ & & & & 0.185 \\
\hline Never & & $63.15(1126)$ & $62.34(879)$ & $66.22(247)$ & \\
\hline Former & & $32.25(575)$ & $33.26(469)$ & $28.42(106)$ & \\
\hline Current & & $4.15(74)$ & $3.97(56)$ & $4.83(18)$ & \\
\hline Alcohol consumption & $1.12(20)$ & $36.34(648)$ & $37.73(532)$ & $31.10(116)$ & 0.019 \\
\hline Living area & $0(0)$ & & & & 0.653 \\
\hline Rural or semi-rural & & $56.25(1003)$ & $56.52(797)$ & $55.23(206)$ & \\
\hline Urban & & $43.75(780)$ & $43.48(613)$ & $44.77(167)$ & \\
\hline Social lifestyle & $0(0)$ & & & & $<0.001$ \\
\hline Alone at home & & $25.86(461)$ & $22.77(321)$ & $37.53(140)$ & \\
\hline Accompanied at home & & 73.75 (1315) & $76.81(1083)$ & $62.20(232)$ & \\
\hline Assisted living facility & & $0.39(7)$ & $0.43(6)$ & $0.27(1)$ & \\
\hline Achievement $\geq 9$ th Grade & $1.51(27)$ & $63.99(1141)$ & $64.47(909)$ & $62.20(232)$ & 0.524 \\
\hline Work history & $0.62(11)$ & $90.91(1621)$ & $91.77(1294)$ & $87.67(327)$ & 0.010 \\
\hline ADL score, M (SD) & $0.34(6)$ & $5.94(0.25)$ & $5.95(0.19)$ & $5.87(0.38)$ & $<0.001$ \\
\hline IADL score, M (SD) & $0.28(5)$ & $3.91(0.47)$ & $3.92(0.44)$ & $3.86(0.54)$ & 0.002 \\
\hline Financial or logistical supports & $0.17(3)$ & 90.24 (1609) & $90.28(1273)$ & $90.08(336)$ & 0.958 \\
\hline Paramedical assistance & $1.18(21)$ & $36.68(654)$ & $33.69(475)$ & $47.99(179)$ & $<0.001$ \\
\hline Arterial disease & $0.39(7)$ & $19.07(340)$ & $18.65(263)$ & $20.64(77)$ & 0.360 \\
\hline Atrial fibrillation & $0.28(5)$ & $39.37(702)$ & $42.34(597)$ & $28.15(105)$ & $<0.001$ \\
\hline High blood pressure & $0.11(2)$ & $77.96(1390)$ & $78.87(1112)$ & $74.53(278)$ & 0.065 \\
\hline Heart failure & $1.18(21)$ & & & & 0.202 \\
\hline No & & $88.67(1581)$ & $88.51(1248)$ & $89.28(333)$ & \\
\hline Mild to moderate heart failure, NYHA I-II & & $7.40(132)$ & $7.80(110)$ & $5.90(22)$ & \\
\hline Severe heart failure, NYHA III-IV & & $2.75(49)$ & $2.48(35)$ & $3.75(14)$ & \\
\hline MMSE score & $15.14(270)$ & & & & 0.040 \\
\hline Probable moderate to severe cognitive impairment, $<\mathbf{2 4}$ & & $4.88(87)$ & $4.47(63)$ & $6.43(24)$ & \\
\hline Probable mild cognitive impairment, [24-27] & & $14.47(258)$ & $13.55(191)$ & $17.96(67)$ & \\
\hline No cognitive impairment, $\geq \mathbf{2 7}$ & & $65.51(1168)$ & $66.24(934)$ & $62.73(234)$ & \\
\hline Parkinson's disease & $0.39(7)$ & $0.73(13)$ & $0.21(3)$ & $2.68(10)$ & $<0.001$ \\
\hline History of severe stroke & $0.45(8)$ & $2.02(36)$ & $1.84(26)$ & $2.68(10)$ & 0.310 \\
\hline Probable clinical depression (GDS-15 score $\geq 10$ ) & $22.27(397)$ & $4.99(89)$ & $4.33(61)$ & $7.51(28)$ & 0.007 \\
\hline History of depressive disorder & $0.06(1)$ & $17.33(309)$ & $10.92(154)$ & $41.55(155)$ & $<0.001$ \\
\hline Thyroid dysfunction & $1.29(23)$ & $10.54(188)$ & $9.57(135)$ & $14.21(53)$ & 0.011 \\
\hline Type 2 diabetes & $0.28(5)$ & $43.02(767)$ & $45.18(637)$ & $34.85(130)$ & $<0.001$ \\
\hline History of severe hypoglycaemia & $1.35(24)$ & $0.62(11)$ & $0.50(7)$ & $1.07(4)$ & 0.259 \\
\hline
\end{tabular}


Table 1 (continued)

\begin{tabular}{|c|c|c|c|c|c|}
\hline General characteristics, \% (n) & Missing, \% (n) & $\begin{array}{l}\text { All } \\
n=1783\end{array}$ & $\begin{array}{l}\text { PDI- } \\
n=1410\end{array}$ & $\begin{array}{l}\text { PDI+ } \\
n=373\end{array}$ & $p^{a}$ \\
\hline Sleep apnea & $0.39(7)$ & $4.82(86)$ & $4.61(65)$ & $5.63(21)$ & 0.417 \\
\hline Pulmonary chronic obstructive disease or fibrosis & $0.39(7)$ & $8.69(155)$ & $8.23(116)$ & $10.46(39)$ & 0.177 \\
\hline History of fall & $0.73(13)$ & $6.62(118)$ & $5.25(74)$ & $11.80(44)$ & $<0.001$ \\
\hline Arthropathy & $0.22(4)$ & $46.83(835)$ & $42.62(601)$ & $62.73(234)$ & $<0.001$ \\
\hline Chronic pain & $0.17(3)$ & $54.23(967)$ & $48.51(684)$ & $75.87(283)$ & $<0.001$ \\
\hline Polypharmacy & $0(0)$ & $57.82(1031)$ & $52.06(734)$ & $79.62(297)$ & $<0.001$ \\
\hline
\end{tabular}

Abbreviations. M (SD) mean (standard deviation), BMl body mass index in $\mathrm{kg} / \mathrm{m}^{2}$, eGFR glomerular filtration rate in $\mathrm{mL} / \mathrm{min} / 1.73 \mathrm{~m}^{2}, A D L$ score Activities of Daily Living score (maximum score 6 indicating no disability in activities of daily living), IADL score Instrumental Activities of Daily Living score (maximum score 4 indicating no instrumental disability), NYHA New York Heart Association, MMSE score Mini-Mental State Examination score (maximum score 30 indicating no cognitive impairment), GDS-15 score 15-item Geriatric Depression Scale score (maximum score 15, the higher, the more important risk of depression), PDI Potentially Driver-Impairing, PDI+ drivers Drivers taking at least one PDI drug, PDI-drivers Drivers without any PDI drug in their treatment

${ }^{a}$ Chi-squared or Fisher's exact test for categorical data, Student's t-test for continuous data and Mann-Whitney test for non-parametric continuous data. A $p$-value $<0.05$ is significant

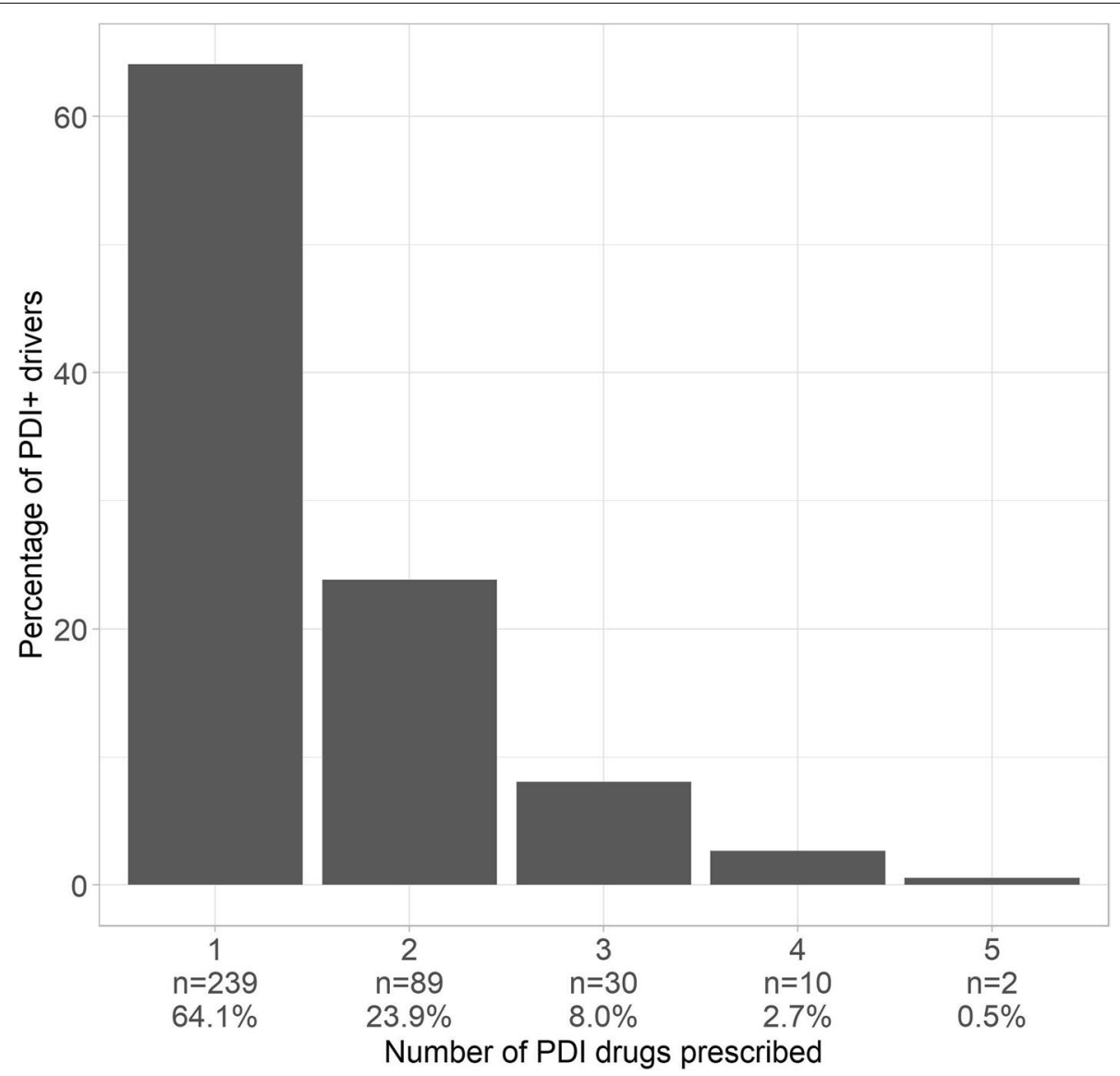

Fig. 2 Rates of PDI+ drivers by number of PDI drugs prescribed. Abbreviations. PDI, Potentially Driver-Impairing; PDI+ drivers, Drivers taking at least one PDI drug

the 5 most frequent PDI drugs prescribed in this study. Indeed, insomnia and anxiety are frequently observed in depressed older people [34], and also described as a risk factor for late life depression [35]. Moreover, previous research found that chronic pain is a risk factor for depression in older adults, and similarly, that depressed 
Table 2 Multivariate analysis of factors associated with PDI-drug consumption in drivers

\begin{tabular}{llll}
\hline & OR & $\mathbf{9 5 \% ~ C l}$ & p-value \\
\hline ADL Score & $\mathbf{0 . 3 4}$ & $\mathbf{0 . 1 7 - 0 . 6 8}$ & $\mathbf{0 . 0 0 2}$ \\
Atrial fibrillation & $\mathbf{0 . 4 8}$ & $\mathbf{0 . 3 2}-\mathbf{0 . 7 1}$ & $<\mathbf{0 . 0 0 1}$ \\
Type 2 diabetes & $\mathbf{0 . 5 4}$ & $\mathbf{0 . 3 7 - 0 . 7 9}$ & $\mathbf{0 . 0 0 1}$ \\
Age & 0.97 & $0.95-1.00$ & 0.066 \\
Female & 1.15 & $0.82-1.62$ & 0.418 \\
Chronic pain & $\mathbf{2 . 3 0}$ & $\mathbf{1 . 5 4 - 3 . 4 6}$ & $<\mathbf{0 . 0 0 1}$ \\
History of depressive & $\mathbf{4 . 2 8}$ & $\mathbf{3 . 0 0 - 6 . 1 4}$ & $<\mathbf{0 . 0 0 1}$ \\
disorder & & & $\mathbf{2 . 0 0 1}$ \\
Polypharmacy & $\mathbf{4 . 3 2}$ & $\mathbf{2 . 9 7 - 6 . 4 1}$ & $<$
\end{tabular}

The model was adjusted for age, sex, history of depressive disorder, polypharmacy, ADL score, and the 3 diseases relating to the sub-cohorts (type 2 diabetes, atrial fibrillation and chronic pain)

Abbreviations. PDI Potentially Driver-Impairing, OR Odds Ratio, 95\% Cl 95\% Confidence Interval, $A D L$ score Activities of Daily Living score (maximum score 6 indicating no disability in activities of daily living) older people were more likely to suffer from chronic pain, corroborating the hypothesis, that neuroinflammation could be a common pathogenic factor of chronic pain and depression [36]. Surprisingly, no antidepressant was found in the 5 most frequent PDI drugs, which may be explained by the fact that only $7.5 \%$ of PDI+ drivers had probable clinical depression (according to their GDS-15 score at inclusion), suggesting that insomnia, anxiety and chronic pain would be residual or prodromal symptoms of depression in these patients. Conversely, PDI+ drivers in this study suffered less frequently from T2DM and AF. This may be explained by a better management of patients suffering from these chronic diseases, with regular revision of prescriptions. Finally, PDI+ drivers had more disability than PDI- ones, which might be driven by the association of symptoms treated with PDI medications (like insomnia, anxiety or chronic pain) and medical comorbidity $[24,27,37]$.

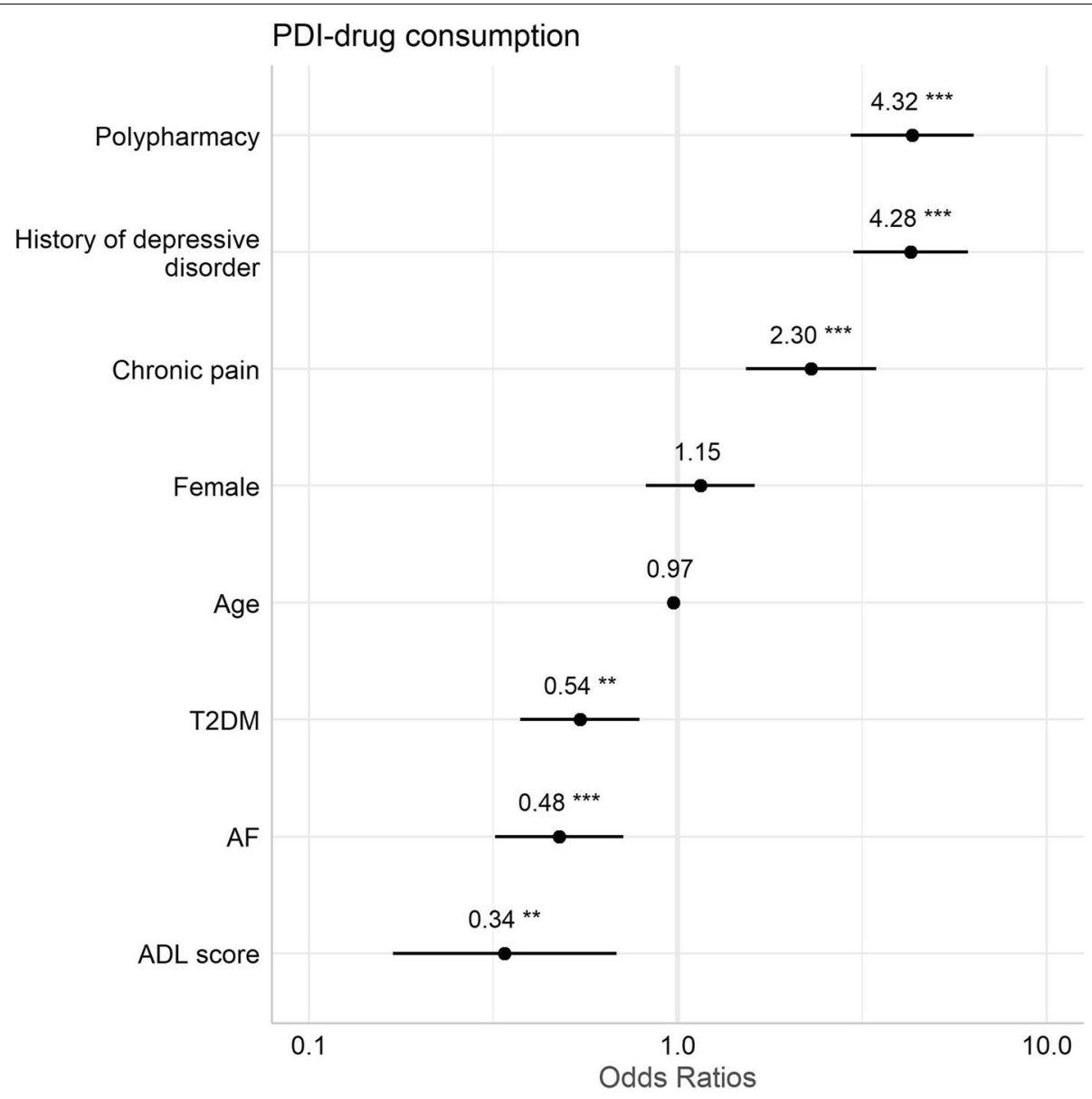

Fig. 3 Multivariate analysis of factors associated with PDI-drug consumption in drivers. Abbreviations. PDI, Potentially Driver-Impairing; T2DM, Type 2 diabetes; AF, Atrial fibrillation; ADL score, Activities of Daily Living score (maximum score 6 indicating no disability in activities of daily living). *, $p<0.05 ;^{* *}, p<0.01 ;{ }^{* * *}, p<0.001$. The model was adjusted for age, sex, history of depressive disorder, polypharmacy, ADL score, and the 3 diseases relating to the sub-cohorts (T2DM, AF and chronic pain) 
These results are a matter of great concern since the increased risk of car accident in drivers taking PDI drugs is widely documented $[8,18,38,39]$, especially for benzodiazepines [8, 40], Z-drug hypnotics [8, 41, 42] and opioids [8, 39, 43, 44]. Furthermore, most of the factors found here associated with PDI-drug consumption in older drivers are also associated with a higher risk of car accident, in particular depression $[6,7]$, chronic pain known to alter performance on attention tasks [45], and polypharmacy $[17,18]$. In the study of Hetland et al., the average medically impaired driver was taking 5.9 (3.7) total routine medications [18], while half of older drivers interviewed for the AAA Foundation for Traffic Safety study were taking seven or more medications [17]. Furthermore, PDI drugs tolerance is more likely to be poorer in older subjects than younger ones because of pharmacokinetic changes associated with ageing, like altered hepatic and renal functions that increase plasma elimination half-life, leading to increase of drug side effects like impaired attention, increased reaction time, hypersomnolence and confusion [46].

The concerning rate of aged drivers taking PDI drug might raise the question of searching for ways to decrease it. If no recommendation can be formally given to GPs based on this study because of several limitations, some aspects of drug prescription in aged population should be noted. First, the results of this study show the importance of questioning patients about their driving habits and considering them before prescribing. They might also highlight the importance of informing the patients and their families about the high risk of car accident while driving under the influence of PDI drugs, either prescribed or used for self-medication. Second, these results should also call for strategies to reduce the prescription of PDI drugs in older drivers and even avoid them when possible, keeping in mind that benzodiazepine and Z-drug hypnotic withdrawal can be achieved in the older population [47]. Whenever possible, alternative therapies should be considered: cognitive behavioral therapy is known to efficiently treat chronic pain [27], depression [36], anxiety [25] and insomnia (with stimulus control, sleep restriction, sleep hygiene and relaxation) [24], also acupuncture, hypnotherapy, physical exercise and relaxation have demonstrated some efficacy in the treatment of chronic pain and depression [36]. Third, since reducing polypharmacy should always be targeted, prescriptions should be regularly revised with the use of geriatrics tools like the Screening Tool of Older Person's Prescriptions (STOPP) [48].

This study has some limitations. First, the results of this study have to be interpreted within the limit of its design. The fact that participants of the S.AGES cohort were included according to three specific diseases (T2DM, AF and chronic pain) might induce an inclusion bias, even though these diseases are highly prevalent in the older population [27, 49, 50]. Besides, Tramadol prescription in this study was probably higher than in the whole French population because one third of the participants were recruited in the chronic pain sub-cohort. Moreover, this study has a cross-sectional design: PDI status of participants may have changed during the follow-up. Another limitation is that the inclusion of the S.AGES data occurred about 10 years ago. The French list of PDI drugs has evolved during the last decade, which may have led to misestimate the number and distribution of such drugs among drivers. Nevertheless, according to the ANSM, in the whole French population in 2015, the rate of subjects taking benzodiazepines was still high $(13.4 \%$ of the French population was prescribed a benzodiazepine at least once) [51]. Regarding the use of opioids, Tramadol consumption (alone or in association) has highly increased (+68\%) between 2006 and 2017 [52]. Nevertheless, these most recent analyses of benzodiazepine (2015) and opioid analgesic (2017) consumptions by the ANSM were calculated from the whole French general population whatever the age, the driving status, and the state of health. They are therefore not easily comparable to descriptive analyses of this study population, which only comprises aged drivers with specific diseases.

Nevertheless, this study has several strengths: it was conducted in real life condition, with a large sample size, and data were recorded by patients' GPs, with extensive socio-demographical, clinical and therapeutic information which gave a precise and detailed description of older drivers' use of PDI drugs.

\section{Conclusions}

This real life study showed a concerning rate of older drivers taking at least one PDI drug. These drivers, in comparison with those not taking any PDI drug, had more disability, more often a history of depressive disorder and were receiving more often polypharmacy. They had more frequently chronic pain and less frequently T2DM and AF. These observations highlight the huge importance for prescribers to frequently revise the relevance of prescribing PDI drugs in older drivers. They also highlight the need to assess driving risks, educate patients, and propose alternatives to maintain independence when driving cessation is raised. GPs are on the frontline to implement such measures, since they are first line health care providers in the older population. General or local authorities may also have a key role in providing alternative solutions to driving especially in rural areas. 


\section{Abbreviations}

US: United States; EU: European Union; PDI: Potentially driver-impairing; GP General practitioner; T2DM: Type 2 diabetes mellitus; AF: Atrial fibrillation; ANSM: French National Agency for Medicines and Health Products; ADL: Activities of Daily Living; IADL: Instrumental Activities of Daily Living; BMI: Body mass index; eGFR: Glomerular filtration rate; NYHA: New-York Heart Association; MMSE: Mini-mental State Examination; GDS-15: 15-item Geriatric Depression Scale; COPD: Chronic obstructive pulmonary disease; INN: International Nonproprietary; ATC: Anatomical Therapeutic Chemical Classification System; $\mathrm{PDI}+$ : Drivers taking at least one PDI drug; PDI-: Drivers without any PDI drug in their treatment; M (SD): Mean (Standard deviation); OR (95\% CI) : Odds Ratio (95\% confidence interval).

\section{Supplementary Information}

The online version contains supplementary material available at https://doi. org/10.1186/s12877-021-02726-5.

Additional file 1. Potentially driver-impairing drugs, categorized in level 2 or 3 of the French classification. Table summarizing potentially driverimpairing drugs categorized in level 2 or 3 of the French classification.

Additional file 2. Number of PDI drugs categorized at level 2 or 3 in the French classification, recorded in the original study. Table summarizing the number of potentially driver-impairing drugs categorized at level 2 or 3 in the French classification, recorded in the original study.

Additional file 3. Multivariate analyses of factors associated with PDIdrug consumption in drivers, respectively in the 3 sub-cohorts. Table summarizing the multivariate analyses of factors associated with potentially driver-impairing drug consumption in drivers, respectively in the 3 sub-cohorts (chronic pain, atrial fibrillation and type 2 diabetes)

\section{Acknowledgments}

The authors thank all of the S.AGES investigators.

\section{Authors' contributions}

Study concept and design: Sarah Zitoun, Edouard Baudouin, Laurent Becquemont, Emmanuelle Duron. Analysis of data: Sarah Zitoun, Edouard Baudouin, Jean-Sébastien Vidal, Laurent Becquemont. Interpretation of data: Sarah Zitoun, Edouard Baudouin, Emmanuelle Corruble, Jean-Sébastien Vidal, Laurent Becquemont, Emmanuelle Duron. Drafting of the manuscript: Sarah Zitoun, Edouard Baudouin, Emmanuelle Corruble, Jean-Sébastien Vidal, Laurent Becquemont, Emmanuelle Duron. The author(s) read and approved the final manuscript.

\section{Funding}

This study was financed and sponsored by SANOFI France.

\section{Availability of data and materials}

The datasets used and/or analysed during the current study are available from the corresponding author on reasonable request.

\section{Declarations}

\section{Ethics approval and consent to participate}

The study was approved by the Ethics committee (Comité de protection des personnes Ile de France XI) on January 15, 2009 (ref 09006) and by the French National Agency for Medicines and Health Products (ANSM) on February 6, 2009 (ref B81333-40) (ClinicalTrials.gov NCT01065909). All methods were performed in accordance with the relevant guidelines and regulations (Declaration of Helsinki). Informed consent was obtained from all individual participants included in the study.

\section{Consent for publication}

$$
\text { Not applicable. }
$$

\section{Competing interests}

LB appeared/appears as principal or co-investigator of several clinical trials from different SPONSORS: Novartis, Actelion, Alnylam Pharmaceuticals, IONIS
Pharmaceutical, Takeda, Novonordisk, Shire, Boehringer. Received fees from Sanofi-Genzyme. SZ, EB, EC, JSV and ED declare that they have no competing interests.

\section{Author details}

${ }^{1}$ University of Paris-Saclay, Inserm, CESP, Team MOODS, 94270 Le Kremlin-Bicêtre, France. ${ }^{2}$ Assistance Publique - Hôpitaux de Paris, Bicêtre Hospital, Department of Psychiatry, 94270 Le Kremlin-Bicêtre, France. ${ }^{3}$ Assistance Publique - Hôpitaux de Paris, Paul Brousse Hospital, Department of Geriatric, 94800 Villejuif, France. ${ }^{4}$ Assistance Publique - Hôpitaux de Paris, Hôpital Broca, F-75013 Paris, France. ${ }^{5}$ Université de Paris, EA 4468, F-75013 Paris, France.

Received: 29 April 2021 Accepted: 13 December 2021

Published online: 03 January 2022

\section{References}

1. World Population Ageing 2019 (ST/ESA/SER.A/444). United Nations, Department of Economic and Social Affairs, Population Division. 2020 https://www.un.org/en/development/desa/population/publications/ pdf/ageing/WorldPopulationAgeing2019-Report.pdf

2. Older drivers. Insurance Institute for Highway Safety, Highway Loss Data Institute. 2020. https://www.iihs.org/topics/older-drivers. Updated September 2020

3. Polders E, Brijs T, Vlahogianni E, et al. ElderSafe - Risks and countermeasures for road traffic of the elderly in Europe. European Commission. 2015 https://ec.europa.eu/transport/road_safety/sites/roadsafety/files/pdf/ studies/eldersafe_final report.pdf. Published December 2015.

4. Cicchino JB, McCartt AT. Trends in older driver crash involvement rates and survivability in the United States: an update. Accid Anal Prev. 2014;72:44-54.

5. Mitchell CGBK. The licensing and safety of older drivers in Britain. Accid Anal Prev. 2013;50:732-41.

6. Marshall SC. The role of reduced fitness to drive due to medical impairments in explaining crashes involving older drivers. Traffic Inj Prev. 2008:9:291-8

7. Hill LL, Lauzon VL, Winbrock EL, Li G, Chihuri S, Lee KC. Depression, antidepressants and driving safety. Inj Epidemiol. 2017;4:10.

8. Rudisill TM, Zhu M, Kelley GA, Pilkerton C, Rudisill BR. Medication use and the risk of motor vehicle collisions among licensed drivers: a systematic review. Accid Anal Prev. 2016:96:255-70.

9. Becquemont L, Benattar-Zibi L, Bertin P, et al. National observatory on the therapeutic management in ambulatory care patients aged 65 and over, with type 2 diabetes, chronic pain or atrial fibrillation. Therapie. 2013;68:265-83.

10. Katz S, Ford AB, Moskowitz RW, Jackson BA, Jaffe MW. Studies of illness in the aged. The index of ADL : a standardized measure of biological and psychosocial function. JAMA. 1963;185:914-9.

11. Barberger-Gateau P, Dartigues JF, Letenneur L. Four instrumental activities of daily living score as a predictor of one-year incident dementia. Age Ageing. 1993;22:457-63.

12. Levey AS, Bosch JP, Lewis JB, Greene T, Rogers N, Roth D. A more accurate method to estimate glomerular filtration rate from serum creatinine: a new prediction equation. Modification of diet in renal disease study group. Ann Intern Med. 1999;130:461-70.

13. Folstein MF, Folstein SE, McHugh PR. "Mini-mental state". A practical method for grading the cognitive state of patients for the clinician. J Psychiatr Res. 1975;12:189-98.

14. Marc LG, Raue PJ, Bruce ML. Screening performance of the 15-item geriatric depression scale in a diverse elderly home care population. Am J Geriatr Psychiatry. 2008;16:914-21.

15. Masnoon N, Shakib S, Kalisch-Ellett L, Caughey GE. What is polypharmacy? A systematic review of definitions. BMC Geriatr. 2017;17:230.

16. Arrêté du 13 mars 2017 modifiant l'arrêté du 8 août 2008 pris pour l'application de l'article R. 5121-139 du code de la santé publique et relatif à l'apposition d'un pictogramme sur le conditionnement extérieur de certains médicaments et produits. Legifrance. 2017. https://www.legif rance.gouv.fr/eli/arrete/2017/3/13/AFSP1708232A/jo/texte. Published 18 Mar 2017. 
17. Hill LL, Andrews H, Li G, et al. Medication use and driving patterns in older drivers: preliminary findings from the LongROAD study. Inj Epidemiol. 2020;7:38.

18. Hetland AJ, Carr DB, Wallendorf MJ, Barco PP. Potentially driver-impairing (PDI) medication use in medically impaired adults referred for driving evaluation. Ann Pharmacother. 2014:48:476-82.

19. LeRoy AA, Morse ML. Department of Transportation. HS 810 858. Multiple medications and vehicle crashes: analysis of databases. 2008 (Accessed Dec 17, 2012)

20. Jerez-Roig J, Medeiros LFB, Silva VAB, et al. Prevalence of self-medication and associated factors in an elderly population: a systematic review. Drugs Aging. 2014;31:883-96.

21. Airagnes G, Pelissolo A, Lavallée M, Flament M, Limosin F. Benzodiazepine misuse in the elderly: risk factors, consequences, and management. Curr Psychiatry Rep. 2016;18:89.

22. Høiseth G, Austdal LE, Wiik E, Bogstrand ST, Mørland J. Prevalence and concentrations of drugs in older suspected drugged drivers. Traffic Inj Prev. 2017;18:231-6.

23. Gerlach LB, Wiechers IR, Maust DT. Prescription benzodiazepine use among older adults: a critical review. Harv Rev Psychiatry. 2018;26:264-73.

24. Patel D, Steinberg J, Patel P. Insomnia in the elderly: a review. J Clin Sleep Med. 2018;14:1017-24

25. Pary R, Sarai SK, Micchelli A, Lippmann S. Anxiety Disorders in Older Patients. Prim Care Companion CNS Disord. 2019;21.

26. Treves N, Perlman A, Kolenberg Geron L, Asaly A, Matok I. Z-drugs and risk for falls and fractures in older adults-a systematic review and metaanalysis. Age Ageing. 2018;47:201-8.

27. Schwan J, Sclafani J, Tawfik VL. Chronic pain Management in the Elderly. Anesthesiol Clin. 2019;37:547-60.

28. Maree RD, Marcum ZA, Saghafi E, Weiner DK, Karp JF. A systematic review of opioid and benzodiazepine misuse in older adults. Am J Geriatr Psychiatry. 2016;24:949-63.

29. Naples JG, Gellad WF, Hanlon JT. The role of opioid analgesics in geriatric pain management. Clin Geriatr Med. 2016;32:725-35.

30. Trescot AM, Datta S, Lee M, Hansen H. Opioid pharmacology. Pain Physician. 2008;11:S133-53.

31. Kaufman G. Polypharmacy in older adults. Nurs Stand. 2011;25:49-55 quiz 58.

32. Hosseini SR, Zabihi A, Jafarian Amiri SR, Bijani A. Polypharmacy among the elderly. J Midlife Health. 2018;9:97-103.

33. Fialová $D$, Laffon $B$, Marinković $V$, et al. Medication use in older patients and age-blind approach: narrative literature review (insufficient evidence on the efficacy and safety of drugs in older age, frequent use of PIMs and polypharmacy, and underuse of highly beneficial nonpharmacological strategies). Eur J Clin Pharmacol. 2019;75:451-66.

34. Lleshi V, Bizzozzero T. La dépression du sujet âgé. Rev Med Suisse. 2009:5:1785-9.

35. Fiske A, Wetherell $\lrcorner$, Gatz M. Depression in older adults. Annu Rev Clin Psychol. 2009:5:363-89.

36. Zis P, Daskalaki A, Bountouni I, Sykioti P, Varrassi G, Paladini A. Depression and chronic pain in the elderly: links and management challenges. Clin Interv Aging. 2017; 12:709-20.

37. Balsamo M, Cataldi F, Carlucci L, Fairfield B. Assessment of anxiety in older adults: a review of self-report measures. Clin Interv Aging 2018;13:573-93.

38. Rudisill TM, Zhao S, Abate MA, Coben JH, Zhu M. Trends in drug use among drivers killed in U.S. traffic crashes, 1999-2010. Accid Anal Prev. 2014;70:178-87.

39. Rudisill TM, Zhu M, Davidov D, et al. Medication use and the risk of motor vehicle collision in West Virginia drivers 65 years of age and older: a casecrossover study. BMC Res Notes. 2016;9:166.

40. Fournier J-P, Wilchesky M, Patenaude V, Suissa S. Concurrent use of benzodiazepines and antidepressants and the risk of motor vehicle accident in older drivers: a nested case-control study. Neurol Ther. 2015;4:39-51.

41. Gunja N. In the Zzz zone: the effects of Z-drugs on human performance and driving. J Med Toxicol. 2013;9:163-71.

42. Nevriana A, Möller J, Laflamme L, Monárrez-Espino J. New, occasional, and frequent use of Zolpidem or Zopiclone (alone and in combination) and the risk of injurious road traffic crashes in older adult drivers: a population-based case-control and case-crossover study. CNS Drugs. 2017:31:711-22.
43. Li G, Chihuri S. Prescription opioids, alcohol and fatal motor vehicle crashes: a population-based case-control study. Inj Epidemiol. 2019;6:11.

44. Chihuri S, Li G. Use of prescription opioids and motor vehicle crashes: a meta analysis. Accid Anal Prev. 2017;109:123-31.

45. Moore DJ, Meints SM, Lazaridou A, et al. The effect of induced and chronic pain on attention. J Pain. 2019;20:1353-61.

46. Mangoni AA, Jackson SHD. Age-related changes in pharmacokinetics and pharmacodynamics: basic principles and practical applications. Br J Clin Pharmacol. 2004;57:6-14.

47. Reeve E, Ong M, Wu A, Jansen J, Petrovic M, Gnjidic D. A systematic review of interventions to deprescribe benzodiazepines and other hypnotics among older people. Eur J Clin Pharmacol. 2017;73:927-35.

48. Gallagher P, Ryan C, Byrne S, Kennedy J, O'Mahony D. STOPP (screening tool of older Person's prescriptions) and START (screening tool to alert doctors to right treatment). Consensus validation. Int J Clin Pharmacol Ther. 2008;46:72-83.

49. Staerk L, Sherer JA, Ko D, Benjamin EJ, Helm RH. Atrial fibrillation: epidemiology, pathophysiology, and clinical outcomes. Circ Res. 2017;120:1501-17.

50. Bellary S, Kyrou I, Brown JE, Bailey CJ. Type 2 diabetes mellitus in older adults: clinical considerations and management. Nat Rev Endocrinol. 2021;17:534-48.

51. Richard N, Benard A, Billioti de Gage S, et al. Etat des lieux de la consommation des benzodiazépines en France. ANSM (Agence Nationale de Sécurité du Médicament et des produits de santé). 2017. https://archi veansm.integra.fr/var/ansm_site/storage/original/application/28274caaaf 04713f0c280862555db0c8.pdf. Published April 2017.

52. Monzon E, Rochar N, Cavalié P, et al. Etat des lieux de la consommation des antalgiques opioïdes et leurs usages problématiques. ANSM (Agence Nationale de Sécurité du Médicament et des produits de santé). 2019. https://www.rfcrpv.fr/wp-content/uploads/2019/03/Rapport-ANSM-etCEIPA-sur-les-antalgiques-opioïdes_usage-et-mésusages.pdf. Published February 2019

\section{Publisher's Note}

Springer Nature remains neutral with regard to jurisdictional claims in published maps and institutional affiliations.

Ready to submit your research? Choose BMC and benefit from

- fast, convenient online submission

- thorough peer review by experienced researchers in your field

- rapid publication on acceptance

- support for research data, including large and complex data types

- gold Open Access which fosters wider collaboration and increased citations

- maximum visibility for your research: over $100 \mathrm{M}$ website views per year

At BMC, research is always in progress.

Learn more biomedcentral.com/submissions 